\title{
Growing points of immunology*
}

\author{
IAN R. MACKAY \\ M.D., F.R.C.P., F.R.A.C.P. \\ Head of the Clinical Research Unit \\ Clinical Research Unit of The Walter and Eliza Hall Institute of Medical Research \\ and The Royal Melbourne Hospital, Victoria, Australia
}

\begin{abstract}
'At a time in history, when the earth was thought to be flat, a complete solution of geography was clearly not possible. Someone might have said: "For each continent that is discovered there are ten continents beyond". It turned out, however, that the earth is round, and by the time the explorers reached Australia on their way around the globe, it was evident that geography was, in principle, solved.... It follows that, similar to geography, biology is finite, and ... in principle solved .... I predict that immunology will be completely solved within 50 years from now' (Jerne, 1969).
\end{abstract}

James Cook, F.R.S., ship's captain, navigator, explorer, geographer, mathematician and scientist, left England in the Endeavour in 1768 to observe the passage of Venus across the face of the sun. This expedition led on to his meticulous explorations of the South Pacific and Australia in 1770 and the making of a major contribution to the 'complete solution of geography'.

By 1770 the science of geography was well established but the science of immunology was unknown. Its founder, Edward Jenner, was a contemporary of James Cook and was employed by Joseph Banks to prepare the biological specimens procured from the South Pacific. LeFanu (1951) wrote that Jenner's skill, dexterity and judgment so pleased Banks that Jenner was offered the post of naturalist for Cook's second voyage in 1772 . Jenner declined for he preferred to practise as a country doctor in his native Gloucestershire - this was a fortunate decision for it led to Jenner's discovery that cowpox infection protected against smallpox infection and the introduction of prophylactic vaccination. Thus born, the infant science of immunology at first grew slowly, for nearly 100 years were to pass before the further discoveries by Pasteur on prophylactic immunization, cellular immunology by Metchnikoff, delayed hypersensi-

* Publication No. 1390 from The Walter and Eliza Hall Institute of Medical Research. tivity by Koch, the description of a selective theory of antibody production by Ehrlich, and discoveries leading to serodiagnosis by Bordet, Widal and Wassermann. So microbiology and immunology became linked as one science, and remain so even today in many traditionalist universities. But these sciences have now diverged, and many of the 'growing points' of immunology - transplantation, cancer immunology and autoimmunity - have little connection with microbiology. So, for immunology to progress to its 'complete solution' we must encourage the development of new, strong and independent Departments and Institutes of Immunology in Universities throughout the world.

This paper is a subjective appraisal of ten of the growing points of immunology-several of these are interrelated, as illustrated in Fig. 1, and three cover the more clinically oriented fields of cancer, transplantation and autoimmunity.

\section{Tmmunological differentiation}

Immunological differentiation is a broad growing point which overlaps into many other sciences including embryology, morphogenesis and oncology: it is concerned with processes by which cells obtain the information which directs them towards specialized function.

For the immunological and haemopoietic system, the ancestral undifferentiated cell appears to originate in blood islands of the yolk sac. In the chick embryo stem cells were shown to enter the thymus and bursa of Fabricius, and this determined the subsequent lymphopoietic activity in these tissues (Moore \& Owen, 1967). Moore \& Metcalf (1970) showed that the system initially worked out in the chicken held also for the mouse and presumably all mammals: pluri-potential stem cells in the yolk sac of the embryo migrate to the liver, the site of foetal haemopoiesis, and later to the bone marrow, the site of adult haemopoiesis. Stem cells migrate also into 


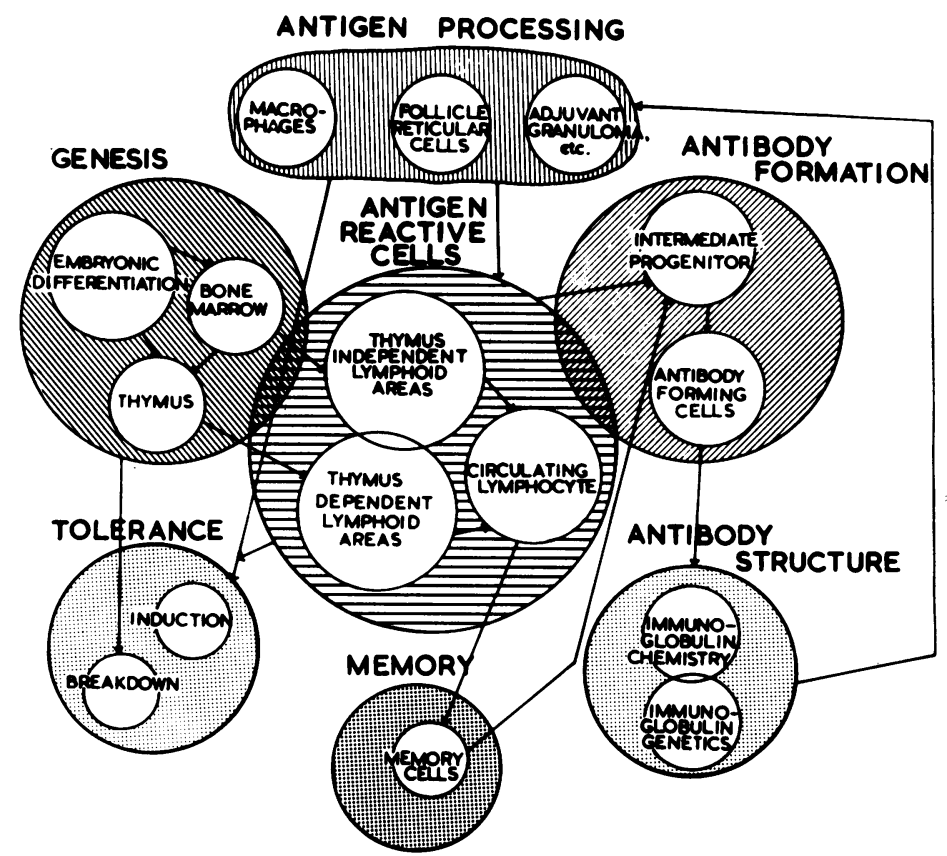

FIG. 1. Diagram illustrating overlap of major 'growing points' of immunology. (By courtesy of Professor G. J. V. Nossal and Academic Press, New York.)

the thymic epithelial anlage, at the early stage of 10-11 days of gestation in the mouse, and presumably enter the human thymus before the 8th week of gestation: their entry is followed by the development of the lymphoid cortex. In adult life stem cells in the bone marrow are the main source of replenishment of haemopoietic and lymphopoietic cell precursors.

Stem cells from the yolk sac, and their descendants in the liver and bone marrow, can be detected by their capacity to form cell colonies in special assay systems in vivo and in vitro. The in vivo assay of colonyforming cells (CFC) depends on their injection into lethally irradiated recipients and the counting of colonies in the spleen. The in vitro assay depends on the stimulation of growth of colonies of granulocytic and monocytic cells in agar culture by a colonystimulating factor, perhaps a leucopoietin, in the urine and serum of man and mouse (Metcalf \& Stanley, 1969). The in vivo CFC is the multipotential stem cell, and the in vitro CFC is a linear descendant from it which gives rise to progenitor cells of the granulocytemonocyte series.

Stem cells and progenitor cells may receive various 'directives' for differentiation. One appears to be an inductive effect of the micro-environment in which the cell finds itself. The second type of 'directive' is represented by 'poietic' agents, e.g. erythropoietin, some of which are formed remotely from their site of action and thus qualify as hormones. The enlarging list of 'poietins' includes erythropoietin, a postu- lated thrombopoietin and leucopoietin, the thymic lymphopoietin which induces lymphoid cells towards immunological competence, the nerve growth stimulating factor, and perhaps even the growth-inhibiting chalones could be grouped with poietins.

An interesting aspect of biology is the evidence for a 'programmed' finite longevity of somatic cells. Hayflick (1968) showed that cultured human embryonic fibroblasts doubled about fifty times and then ceased dividing, and fibroblasts from adults underwent even fewer doublings in culture, 14-29, suggesting that they had already 'used up' some of their doubling potential. If, as seems likely, stem cells were similarly 'programmed' for a finite number of divisions, then exhaustion of stem cells would become the ultimate life-limiting process.

\section{Destination of antigens in lymphoid tissues}

Tracing the destination of antigens after their entry into the body became a major topic of study at the Hall Institute when techniques were developed for the isolation, purification and isotopic labelling of immunogenic proteins from bacterial flagella (Ada et al., 1967; Nossal, 1969).

Studies by radioautography on the popliteal lymph node showed that labelled flagellin first appeared in the circular sinus and then successively in the two functionally separate compartments of the node, the medullary sinus-macrophage compartment and the cortical lymphoid follicle compartment. Localization 
and degradation of antigen in the medullary sinus compartment was the initial and essential process for immune induction and antibody formation. Electron microscopy revealed that labelled antigen entered medullary macrophages both by pinocytosis and direct penetration of the plasma membrane and became enclosed and degraded within phagolysosomes. The pathway by which degradaded antigen leaves the medullary macrophages and initiates cellular proliferation and immune induction is still uncertain.

Localization of antigen in the cortical follicular compartment occurs particularly when either 'natural' or specific antibody is present in the circulation or when antigen is injected as a complex with antibody. Thus attachment of antibody to antigen determines follicular localization, and this property of antibody resides in the Fc piece of the antibody molecule. Cortical follicles comprise a network or web of dendritic processes of reticular cells, the meshes of which contain a migrating transient population of small lymphocytes. Antigen is held for weeks or more in the web on the surface of the dendritic processes as membrane-associated particles, indicating that the cortical compartment serves as an antigen depot and thus has a 'controlling' function in the immune response: follicular localization could effect prolongation of the immune response and development of immunological memory, and under certain circumstances could facilitate induction of immune tolerance (see below).

\section{Activities of lymphocytes}

The drab appearance of lymphocytes belies their manifold activities (Meuwissen, Stutman \& Good, 1969). They are a heterogeneous population comprising: (1) undifferentiated stem cells, (2) long-lived recirculating cells of thymic origin concerned with cellular immunity, (3) short-lived cells of marrow origin concerned with humoral immunity, and (4) sessile cells of the lymphoreticular tissues.

The 'growing point' of lymphocyte activity was greatly stimulated by studies on the recirculation and traffic of lymphocytes in and out of thymus, bone marrow and lymphoid tissue (Gowans \& McGregor, 1965; Ford \& Gowans, 1969). The population of small lymphocytes is derived in embryonic life from stem cells of bone marrow origin which undergo 'numerical expansion' and differentiation to immune competence in the thymus: a proportion of uncertain dimensions is exported as the "peripheral lymphocyte pool'. This pool becomes supplemented by memory cells produced in post-natal life when antigen reacts with thymus-derived lymphocytes. These long-lived lymphocytes recirculate by leaving post-capillary venules in lymphoid tissues, trickle through the subsubstance of lymph nodes to the medullary sinuses, to the efferent lymphatic, and thence re-enter the blood stream. Recirculation provides specifically reactive lymphocytes with every opportunity to meet their relevant antigen.

There appear to be two functionally separate lineages of reactive lymphocytes. These are called thymic (T) and bursal (B) (Roitt et al., 1969), because one lineage subserving mainly cellular immunity is differentiated towards antigen reactivity by the thymus and the other subserving humoral immunity by the presumed mammalian analogue of a primary lymphoid organ in birds called the bursa of Fabricius (Warner \& Szenberg, 1964) (Fig. 2). The site of the mammalian bursal equivalent is unknown, but could be the intestinal epithelium. Additional evidence for these two lineages in man is provided by immune deficiency diseases which illustrate independent deficiencies of cellular or humoral immune functions. Collaborative activities between cells of the two lineages are described below.

The recognizing function of lymphocytes is effected by specific receptors distributed as patches on the cell surface (Mandel, Byrt \& Ada, 1969). These receptors can be 'inactivated' by antisera to immunoglobulins. Although the receptor has been non-committally called ' $I g X$ ', it is now known that the receptor on lymphocytes involved in humoral immunity (B-lymphocytes) is an IgM molecule (Warner, Byrt \& Ada, 1970), whereas for lymphocytes involved in cellular immunity (T-lymphocytes) it may be a new immunoglobulin class (Mason \& Warner, 1970). Attachment of antigen to these receptors acts as a proliferative and mitogenic stimulus and this may be the initiating event in the immune response. Conversely inactivation of these receptors may 'tolerize' the cell.

The generic name of 'lymphokine' has been given to a number of soluble factors produced by activated lymphocytes (Dumonde et al., 1969), including mitogenic factor, macrophage inhibitory factor, cytopathic factor, inflammatory factor and transfer factor. Lymphokines, once produced, are active in the absence of the cells which produced them. The mitogenic factor stimulates DNA metabolism and division of lymphocytes, the cytopathic factor damages monolayers of target cells, the macrophage inhibitory factor (MIF) inhibits the migration of macrophages in vitro, and the 'transfer factor' confers specific reactivity on non-sensitized lymphocytes (Valentine \& Lawrence, 1969). The macrophage inhibition effect is being used increasingly as an in vitro test for specifically sensitized lymphocytes and delayed sensitivity.

\section{Antigen-reactive (antigen-sensitive) cells}

The concept of the 'antigen-sensitive' or 'antigenreactive' cell arose in 1965 from experiments in which 


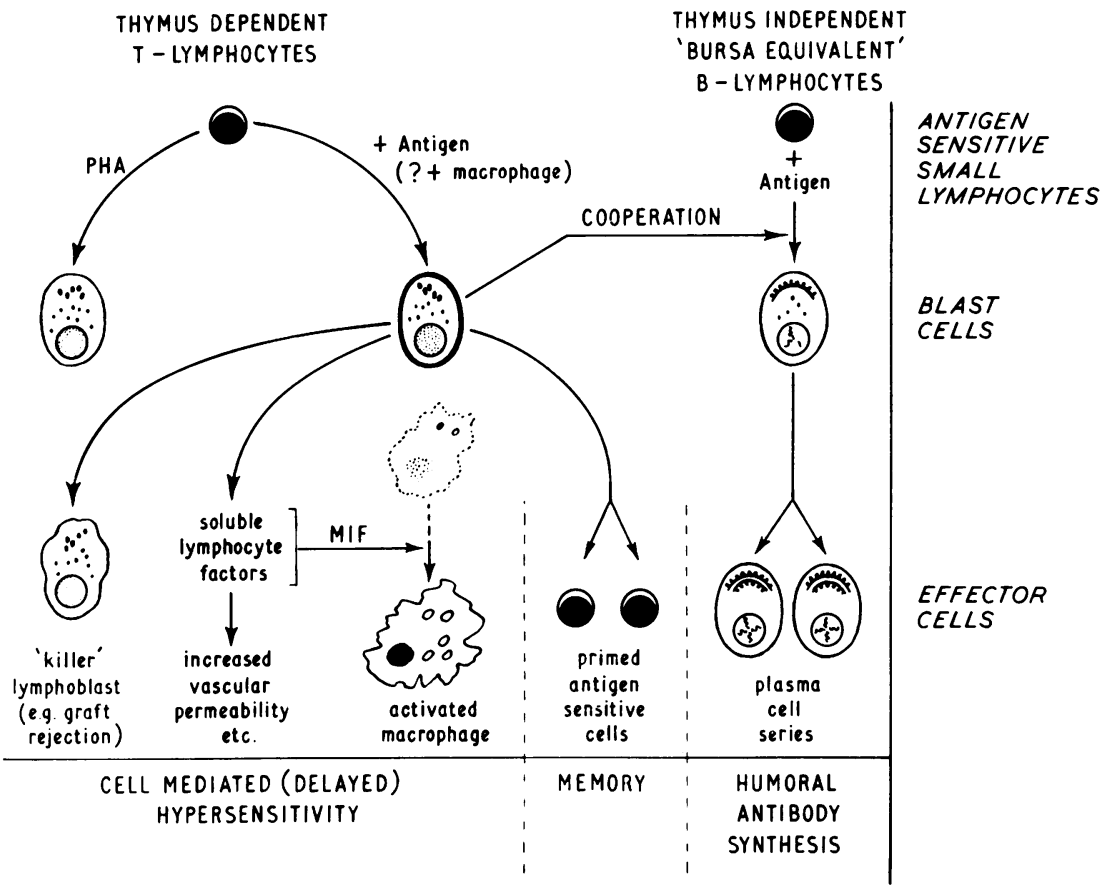

Fig. 2. Role of T-lymphocytes and B-lymphocytes in immunological responses. Many of the events involve active cell proliferation, but for simplicity this has only been indicated at two stages. (By courtesy of Professor I. M. Roitt and the Editor of Lancet.)

lymphoid cells were injected intravenously with an antigen, sheep red cells, into a syngeneic recipient whose immune system had been destroyed by Xirradiation. After 8 days the recipient's spleen contained colonies of cells capable of causing lysis of sheep red cells - these colonies had presumably arisen from proliferation of single 'antigen-reactive' cells in the lymphoid inoculum.

It was implicit in Burnet's original clonal selection theory that there existed a 'unispecific' cell which proliferated in response to stimulation by its corresponding antigen. This cell is the 'immunologically competent cell' of Medawar, the ' $\mathrm{X}$ ' cell in the $X-Y-Z$ scheme (Sercarz \& Byers, 1967) and the antigen-reactive cell in modern parlance (Miller \& Mitchell, 1969). It is a cell not actually engaged in an immune response but fully capable of responding specifically by proliferation when appropriately stimulated by antigen. Differentiation for antigenreactivity is thought to occur in the thymus because the immunodepressive effects of neonatal thymectomy in mice are associated with profound reduction in the numbers of antigen-reactive cells. Undifferentiated stem cells from the bone marrow proliferate and differentiate, perhaps under the influence of a thymic 'lymphopoietin' and are exported as antigen-reactive long-lived recirculating lymphocytes. The number of antigen-reactive cells is increased after antigenic contact, such cells being called 'memory cells'; as memory cells develop, the thymus becomes dispensable.

The various methods for demonstrating antigenreactive cells in vitro include the reactivity of such cells with sheep erythrocytes-rosette-forming cells (McConnell et al., 1969) - and with radioactively labelled antigens including flagellin. The latter method enables such cells to be demonstrated in human peripheral blood (Dwyer \& Mackay, 1970). Blood lymphocytes are mixed with radioiodine-labelled flagellin and cell smears are examined by radioautography-a proportion of cells have labelled antigen specifically bound to their surface (Fig. 3). These 'antigen-binding lymphocytes' were demonstrated in the human foetal spleen (1/2000 lymphocytes) and blood of non-immunized adults in whom there is 'natural' antibody to flagellin (3-5/1000 lymphocytes); their number in the blood increased eight-fold 7-10 days after immunization with flagellin.

\section{Cell collaboration in immune responses}

The concept of cell collaboration in immune responses was introduced 10 years ago in relation to macrophage-lymphocyte interaction (Fishman, 1961). Hitherto macrophages had been regarded simply as 'scavengers' with no specific role in im- 


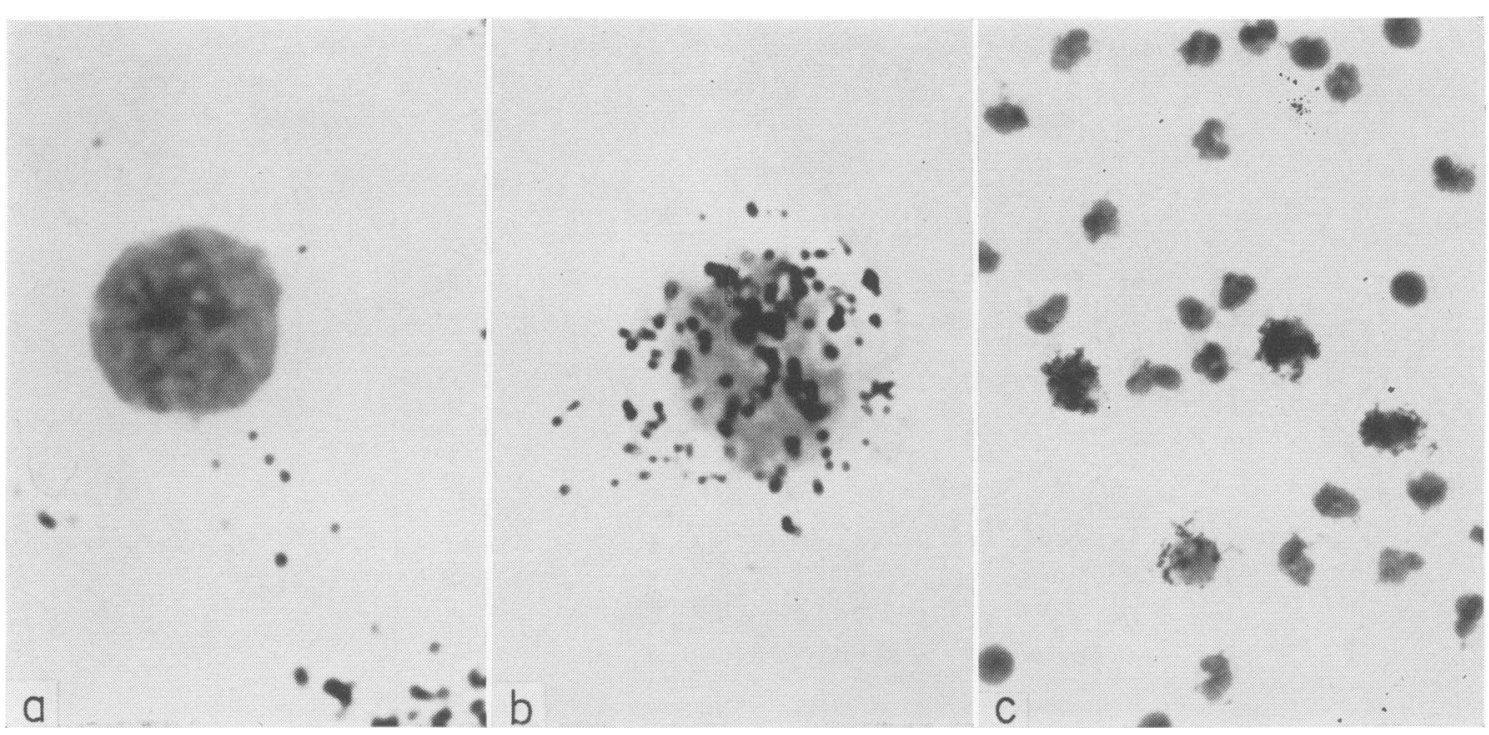

FIG. 3. Antigen-binding lymphocytes demonstrable in human blood using radio-iodine-labelled flagellin and radioautography. (a) Unlabelled lymphocyte; (b) labelled lymphocyte-grains of radioactivity on surface indicate reaction with labelled antigen; and (c) numerous labelled lymphocytes in human peripheral blood during immune response to flagellin. (By courtesy of Dr J. M. Dwyer.)

munity. Fishman (1961) showed that incubation of antigen ( $\mathrm{T} 2$ bacteriophage) with macrophages yielded a product which was sensitive to ribonuclease and which stimulated the production by cultured lymph node cells of antibody to T2 phage: thus antigen 'processing' by macrophages was presumed to be a necessary albeit non-specific step in the induction of an immune response. 'Processing' was not thought to depend on the formation of informational RNA but on a highly stimulatory complex of antigen with RNA - a 'super-antigen'. Subsequent work corroborated that macrophage-processing could augment 'antigenicity', and in the many recent studies on primary immune responses in vitro, mostly using mouse spleen cells and sheep erythrocytes as antigen, macrophages were essential. However, in vitro studies with less complex antigens such as flagellin showed that an immune response could occur without intervention by macrophages. The ready, although not necessarily the right, answer to the macrophage question is that processing is necessary for complex antigens such as sheep red cells which require to be degraded to smaller antigenic fragments but is not obligatory for stimulation by small antigens.

Another important collaborative activity is that between the antigen-reactive cell of thymic origin and a cell derived from the bone marrow (Claman \& Chaperon, 1969; Miller, 1969). In experiments on immunological reconstitution of lethally irradiated animals it was found that neither thymus nor marrow cells alone effectively restored capacity for antibody production: both types were required. Thus, for the sheep red cell antigen at least, thymic antigen-reactive lymphocytes proliferate in response to antigen and thereafter induce another cell derived from the bone marrow to proceed on to antibody production. We do not know whether this bone marrow cell is an antigen-specific bursal-type lymphocyte, nor do we know the basis for this collaborative activity. The thymic cell could act as an 'antigen-focussing' cell, be a source of subcellular immunological information, or simply effect stimulation of its marrow-derived partner by one of its several soluble products.

\section{Immune tolerance}

From the early observations on immune paralysis in 1946, until recently, all forms of acquired immunological 'unresponsiveness' seemingly resulted from the immune apparatus being overloaded and thereby paralysed by antigen. Natural tolerance was attributed to either disappearance or functional inactivation of the specifically reactive lymphoid cellclonal selection theory maintained that immunocytes at a certain stage of their development were highly sensitive to antigen in excess and were thereby deleted. Whatever the mechanism, the continued presence of the tolerizing antigen in the body seemed essential for tolerance to be maintained. It was established that the lymphocyte population expressed the property of tolerance because of the adoptive transference of tolerance by lymphocytes from tolerant animals and the restoration of reactivity in 'tolerized' animals by transference of appropriately reactive lymphocytes.

A new aspect to tolerance was created in 1964 by 
its induction in mice, using bovine serum albumin, in two separate zones of dosage (Dresser \& Mitchison, 1968). There was the conventional 'high zone' type of paralysis with large doses of antigen, and a 'low zone' tolerance occurred when antigen in microgram doses was given repetitively over several weeks. 'Low zone' tolerance was thereafter demonstrated for various other antigens, including flagellin: fragment A of flagellin (Ada \& Parish, 1968) induced low zone tolerance when injected daily into adult rats in the remarkably low dose of $10^{-10} \mu \mathrm{g}$. Three suggestions have been recently made about low zone tolerance. One is that it may depend on antigen which has escaped 'processing' by macrophages. The second is that it may be induced by so few molecules of antigen relative to the lymphocyte population that there must be an 'amplification mechanism', perhaps associated with a depot of antigen in cortical follicles to which circulating lymphocytes are recurrently exposed (Ada \& Parish, 1968). The third is that small amounts of antibody combined with antigen can inactivate immunocompetent cells in vitro and this may be a mechanism of tolerogenesis in vivo (Feldmann \& Diener, 1970).

\section{Immunoglobulins and immunogenetics}

The understanding of the molecular structure and heterogeneity of immunoglobulins (Edelman \& Gall, 1969; Warner, 1969) began in 1959 with Porter's enzymatic fragmentation of the gamma globulin molecule and this led to the recognition of the light and heavy chain structure of immunoglobulins. The amino acid composition of different antibody molecules was shown to differ, pointing to a chemical basis for antibody specificity. Recently the sequencing of the amino acids in isolated light chains led to the discovery that the light chain had differing variable (V) and constant (C) segments: the sequence of amino acids in the variable segment differed from one chain to another, whereas the sequence in the constant segment was always the same. It is the variable segment which forms the combining site for antigens, giving further indication that antibody specificity depends upon molecular structure. Sequencing work on the longer heavy chains has been slower but the picture is similar: there is a variable segment similar in size to that of light chains, and this is likewise associated with the antigen combining site.

One gene or cistron presumably codes for the constant segment of all light and heavy chains of molecules of any one particular class. However, one of the most intriguing of the problems of immunology is the genetic coding process responsible for all the different variable segments of immunoglobulin molecules, for on this depends the 'generation of diversity' characteristic of the antibody population. The mutational theory holds that the cistron respons- ible for the variable segment is subject to frequent random somatic mutations, each of which provides for a different light chain structure and hence a different antibody specificity: cells which contain genes coding for specificities appropriate to the requirements of immunity undergo preferential selection. The germ-line theory holds that all the genetic information required for the construction of all antibody molecules is present in the fertilized ovum and is transmitted to immunoglobulin-producing cells, with individual cells undergoing phenotypic restriction and expressing few or only one antibody specificity.

\section{Transplantation immunology}

An organ grafted from one individual to another encounters the 'histocompatibility barrier': it is recognized as foreign, there is sensitization of the host, and rejection of the graft.

Recognition depends on a cell surface 'mosaic' of histocompatibility antigens; this complex mosaic confers antigenic uniqueness on all individuals except monozygous twins. Histocompatibility antigens are inherited mainly by an extremely complex chromosome locus, HL-A (Van Rood, 1969).

Most, if not all, histocompatibility antigens are on leucocytes, and as such can be recognized with specific antisera from multiparous women. This complex system of leucocyte antigens is determined genetically at a single locus, known as HL-A, which comprises three closely linked subloci with five to eight alleles at each (Walford, 1969). Ting \& Morris (1970) suggested that the genetic control of the HL-A system may be analogous to that of other cell surface antigens, e.g. $\mathrm{ABH}$ antigens, and that $4 \mathrm{a}$ and $4 \mathrm{~b}$ may be precursor substances controlled at a separate locus to the loci controlling the other leucocyte antigens, the specificities of which are derived from gene action on these precursor substances. Biochemical purification of histocompatibility antigens will be needed to resolve this. Despite the complexity of the HL-A system, matching of donors and recipients in renal transplantation significantly influences the survival of an organ graft.

Recognition of foreignness occurs when patrolling long-lived lymphocytes encounter differing histocompatibility antigens on cells of the graft. Lymphocytes capable of recognizing histocompatibility antigens are disproportionately well represented in the small lymphocyte population (Jerne, 1970), suggesting that the capacity during evolution to recognize histocompatibility antigens must have conferred strong survival advantages. Burnet speaks of a 'surveillance' function of lymphocytes whereby the recognition of minor antigenic differences from 'self' serves as a host defence against cancer. Jerne reasoned that the histocompatibility antigens may 
have an even more fundamental significance: they may govern the entire process of stimulation, suppression and selection for mutants within the lymphocyte population.

Sensitization, which follows recognition, is the process whereby there is augmentation of the 'inbuilt' or predetermined capacity of lymphocytes to react with foreign histocompatibility antigens, and this leads to destruction of the graft. It is debated whether sensitization occurs 'peripherally' or 'centrally'. Peripheral sensitization implies that the reactive lymphocyte undergoes blast cell transformation and proliferation in the graft itself, as exemplified by the 'mixed lymphocyte reaction' in vitro between allogeneic lymphocytes; transformed lymphocytes then migrate to lymphoid tissues and increase in number, either by mitosis, recruitment or both. Central sensitization implies that histocompatibility antigens are transported by lymphatics to regional nodes and there induce sensitization.

Rejection is effected mainly by sensitized cytotoxic lymphocytes which invade and destroy the graft (Hall, 1969; Najarian \& Foker, 1969). Humoral antibody also may participate, as there is deposition of immunoglobulin and complement demonstrable by immunofluorescence in vessels and glomeruli of kidneys undergoing rejection (McKenzie \& Whittingham, 1968). Circulating antibody may be more responsible for 'second set' and hyperacute rejection - 'white grafts'. Moreover, antibody may cause the pronounced intimal thickening which eventually produces the 'pin-hole' arterial lumen seen in vessels of chronically rejected kidneys, livers and hearts; resemblances here to the arteriopathy of certain autoimmune diseases and even spontaneous arteriosclerosis are intriguing.

\section{Immunity and cancer}

This growing point was well reviewed by a World Health Organization Scientific Group (1966) who emphasized the abundant evidence for tumour immunity in animals and the lack of such evidence in man.

In animals, tumours induced by chemical carcinogens, e.g. methylcholanthrene, or viruses, e.g. polyoma virus, elicit strong immune responses which inhibit the growth and transplantation of the tumour, and tumour induction is facilitated by immunodepressive procedures such as neonatal thymectomy. The antigens in tumours induced by viruses and chemicals are new tumour antigens which develop with the neoplasm. In inbred mice, in which histocompatibility differences can be excluded, cancer-free animals can immunologically resist the transplantation of cells of tumours induced by viruses and chemicals, and rejection of transplanted tumours is more efficient after previous immunization with extracts of the tumour. In addition, immunity to the induction of tumours can be transferred adoptively by injection of lymphocytes, and 'immune' lymphocytes in vitro destroy tumour cells to which they have become sensitized.

Immunity to cancer in man is evidenced by hyperplastic reactions in regional lymph nodes and lymphoid infiltration within the tumour. A successful immune response explains the well-documented examples of 'spontaneous' regression of cancers, especially neuroblastomas, hypernephromas, choriocarcinomas and malignant melanomas. Conversely declining immune responsiveness with ageing is said to account for the rising incidence of cancer in later life and, as more direct evidence, there is the occurrence of malignancies, mostly lymphoreticular, in immunosuppressed recipients of kidney grafts; fourteen such examples have been observed.

The immune response to human cancer may have diagnostic if not prognostic importance. A carcinoembryonic antigen (CEA) occurs exclusively in adenocarcinomas arising from the gastrointestinal tract and foetal digestive tissues, and $70 \%$ of patients with cancer of the digestive system have serum antibodies to CEA (Thomson et al., 1970). However, after tumour metastasis antibodies to CEA disappear, presumably because of their absorption in vivo. Moreover, CEA itself can be detected by radioimmunoassay in amounts as small as $2.5 \mathrm{ng} / \mathrm{ml}$; the presence in patients with large bowel cancer of CEA in the serum could be a most useful diagnostic test, and the disappearance of CEA antibodies from serum after surgery would indicate recurrence or metastasis of the tumour. Comparable findings were obtained with malignant melanoma. Over $80 \%$ of patients with non-disseminated disease had antibodies-autoantibodies-which reacted with the cells of the patient's own tumour (Lewis et al., 1969). Two types of antibody occurred concordantly, one to a cytoplasmic constituent and one to cell surface membrane, and both disappeared as the disease became widely disseminated.

Immunotherapy of malignant disease, especially leukaemia, is being pursued both by non-specific augmentation of immune responsiveness, using BCG vaccine or pertussis vaccine, and by specific immunization with living or dead leukaemic cells. Skurkovich et al. (1969) treated twelve children with acute leukaemia by parenteral injections of allogeneic leukaemic leucocytes in an attempt to stimulate an 'active' anti-leukaemic immune response; success was claimed in eight of the twelve subjects, but details were insufficient for full assessment of such treatment. Mathé (1969) reported on non-specific augmentation of immunity with BCG vaccine and on specific immunization with killed pooled allogeneic leukaemic cells; these measures appeared to decrease the relapse rate after chemotherapy. 


\section{Autoimmunity and immunosuppression}

Autoimmunity, which was quite unknown as a cause of human disease less than 25 years ago, accounts today for many if not most of the conditions then listed as 'of unknown aetiology'.

Answers can be given (Mackay, 1968, 1969) to many of the frequently-asked questions about autoimmune disease-'how is it defined?' 'can autoimmunity be accepted as a pathogenic process?' 'what are the target tissues?' 'what are the mechanisms of damage?' 'what are the essential histological appearances?' and 'what are the criteria for diagnosis?' However, we lack answers to two important questions-'how does autoimmunization occur?' and 'how can the autoimmune process be arrested?'

There are many possible causes of autoimmunity. The effect of Freund's adjuvant in the production of experimental thyroid and brain disease is well recognized but is there an equivalent process in man? Viral infection is alleged to cause autoimmune disease in animals, e.g. NZB mice, but does it do so in man? Micro-organisms with antigens similar to those of body components are claimed to break tolerance and so cause chronic rheumatic carditis. Drugs induce states of autoimmunity, e.g. alpha-methyldopa which induces haemolytic anaemia and procaine amide which induces lupus-is this a general or quite unique type of drug effect? Genetic predisposition appears important as judged by family studies in man and hybridization of NZB mice. It must be assumed that many environmental influences are capable of transiently breaking immune tolerance in man, and, in a genetically susceptible subpopulation in which females predominate, such influences are sufficient to induce a self-sustaining autoimmune process.

Clinicians dealing with autoimmune disease have taken heart from observations that drugs such as azathioprine and cyclophosphamide can induce tolerance in animals to various test antigens and can suppress experimental autoimmune diseases. The current uncritical application of immunosuppressive treatment in the absence of valid controlled studies is to some degree understandable because autoimmune diseases are infrequent; multicentre trials are difficult to arrange; several effective immunosuppressive agents exist-azathioprine, cyclophosphamide, chlorambucil, methotrexate and antilymphocyte serumand assessment of each in turn is a formidable task; the giving of these drugs with prednisolone has made it difficult to dissociate the effects of the two agents; finally immunosuppressive drugs are usually used as a 'last-ditch' approach or in late 'steroid resistant' phases of disease. Although objective and controlled data comparing azathioprine and prednisolone are accruing for certain diseases including adult glomerulonephritis, active chronic hepatitis and rheumatoid arthritis, more well-designed trials are urgently needed.
The pathways whereby immunosuppressive drugs exert their effect are being explored, experimentally and clinically. Azathioprine and prednisolone in recipients of renal grafts were shown to influence the primary immune response only slightly, but interfered markedly with priming for the secondary response and development of immunological memory (Rowley, Mackay \& McKenzie, 1969). Antilymphocyte serum (ALS), a supplementary immunosuppressive used in transplantation, inactivates the long-lived thymus-derived lymphocytes-it could be likened to 'chemical' thymectomy. The capacity of ALS to prolong skin grafts in animals is fully established and, although difficult to assess in man, does appear to retard graft rejection and permit lower doses of immunosuppressive drugs. There are no worthwhile reports on ALS in human autoimmune disease.

\section{Conclusions}

'Growing points' is rather an understatement for immunology which is expanding in all directions. Ten major areas of interest were selected for discussion:(1) immunological differentiation, (2) antigen localization, (3) activities of lymphocytes, (4) antigenreactive cells, (5) cell collaboration, (6) immune tolerance, (7) immunoglobulins and immunogenetics, (8) transplantation, (9) immunity and cancer, and (10) autoimminity and immunosuppression-but this list is as subjective as newspaper listings of, say, 'England's ten greatest cricketers' or 'the world's ten best-dressed women'. Strong claims for inclusion could be made on behalf of invertebrate immunology, delayed hypersensitivity, allergy and immunoglobulin $\mathrm{E}$, complement components and regulatory mechanisms in immune responses. Probably James Cook in his voyages 200 years ago dallied along those coasts that appealed to him and neglected others no less interesting or important-as was done in this review which dwelt more particularly on the Australian shorelines in the global map of immunology.

\section{Acknowledgments}

The author was in receipt of a grant from the National Health and Medical Research Council of Australia.

\section{References}

ADA, G.L. \& Parish, C.R. (1968) Low zone tolerance to bacterial flagellin in adult rats: a possible role for antigen localized in lymphoid follicles. Proceedings of the National Academy of Sciences of the United States of America, 61, 556.

Ada, G.L., Parish, C.R., Nossal, G.J.V. \& AbBot, A. (1967) The tissue localization, immunogenic, and toleranceinducing properties of antigens and antigen-fragments, Cold Spring Harbor Symposia on Quantitative Biology, 32. 381. 
Claman, H.N. \& Chaperon, E.A. (1969) Immunologic complementation between thymus and marrow cells-a model for the two-cell theory of immunocompetence. Transplantation Reviews, 1, 92.

Dresser, D.W. \& Mitchison, N.A. (1968) The mechanism of immunological paralysis. Advances in Immunology, 8, 129.

Dumonde, D.C., Wolstencroft, R.A., Panayi, G.S., Matthew, M., Morley, J. \& Howson, W.T. (1969) Lymphokines: non-antibody mediators of cellular immunity generated by lymphocyte activation. Nature (London), 224, 38.

DWYER, J.M. \& MACKAY, I.R. (1970) Antigen-binding lymphocytes in human blood. Lancet, $i, 164$.

Edelman, G.M. \& Gall, W.E. (1969) The antibody problem. Annual Review of Biochemistry, 38, 415.

FishmaN, M. (1961) Antibody formation in vitro. Journal of Experimental Medicine, 114, 837.

Feldmann, M. \& Diener, E. (1970) Antibody-mediated suppression of the immune response in vitro. I. Evidence for a central effect. Journal of Experimental Medicine, 131, 247.

FoRD, W.L. \& Gowans, J.L. (1969) The traffic of lymphocytes. Seminars in Hematology, 6, 67.

GowaNs, J.L. \& MCGREGoR, D.D. (1965) The immunological activities of lymphocytes. Progress in Allergy, 9, 1.

HALL, J.G. (1969) Effector mechanisms in immunity. Lancet, i, 25.

HaYflick, L. (1968) Human cells and aging. Scientific American, 218, 32.

JERNE, N.K. (1969) The complete solution of immunology. Australian Annals of Medicine, 18, 345.

JERNE, N.K. (1970) The generation of self-tolerance and of antibody diversity. Proceedings of the National Academy of Sciences of the United States of America (In press).

LEFANU, W.R. (1951) A Bio-Blbliography of Edward Jenner, 1749-1823. Harvey \& Blythe, London.

Lewis, M.G., Ikonopisov, R.L., NaIRN, R.C., Phillips, T.M., Hamilton Fairley, G., Bodenham, D.C. \& Alexander, P. (1969) Tumour-specific antibodies in human malignant melanoma and their relationship to the extent of the disease. British Medical Journal, 3, 547.

Mackay, I.R. (1968) Autoimmune disease in humans. Proc. XIth Congr. int. Soc. Blood Transf., Sydney 1966; Bibliotheca Haematologica, 29, 463.

MACKAY, I.R. (1969) Autoimmune disease. Medical Journal of Australia, i, 696.

MANDEL, T., BYRT, P.N. \& ADA, G.L. (1969) A morphological examination of antigen-reactive cells from mouse spleen and peritoneal cavity. Experimental Cell Research. 58, 179.

MASON, S. \& WARNER, N.L. (1970) The immunoglobulin nature of the antigen recognition site on cells mediating transplantation immunity and delayed hypersensitivity. Journal of Immunology (In press).

Mathe, G. (1969) Approaches to the immunological treatment of cancer in man. British Medical Journal, 4, 7.

McConnell, I., Munro, A., Gurner, B.W. \& CoOmbs, R.R.A. (1969) Studies on actively allergized cells. I. The cyto-dynamics and morphology of rosette-forming lymph node cells in mice and inhibition of rosette-formation with antibody to mouse immunoglobulins. International Archives of Allergy and Applied Immunology, 35, 209.

MCKenZIE, I.F.C. \& WhitTingham, S. (1968) Deposits of immunoglobulin and fibrin in human allografted kidneys. Lancet, ii, 1313.

Metcalf, D. \& Stanley, E.R. (1969) Quantitative studies on the stimulation of mouse bone marrow colony growth in vitro by normal human urine. Australian Journal of Experimental Biology and Medical Science, 47, 453.

Meuwissen, H.J., Stutman, O. \& Good, R.A. (1969) Functions of the lymphocytes. Seminars in Haematology, 6, 28.

MILlER, J.F.A.P. (1969) Thymus and immunocompetence. Australian Journal of Science, 32, 87.

MilleR, J.F.A.P. \& Mitchell, G.F. (1969) Thymus and antigen-reactive cells. Transplantation Reviews, $1,3$.

MOORE, M.A.S \& MetCALF, D. (1970) Ontogeny of the haemopoietic system. Yolk sac origin of in vivo and in vitro colony forming cells in the developing mouse embryo. British Journal of Haematology, 18, 279.

MOORE, M.A.S. \& OWEN, J.J.T. (1967) Experimental studies on the development of the thymus. Journal of Experimental Medicine, 126, 715.

NAJARIAN, J.S. \& FoKer, J.E. (1969) Mechanisms of kidney allograft rejection. Transplantation Proceedings, 1, 184.

NossaL, G.J.V. (1969) The cellular basis of immunity. Harvey Lectures, 63, 179.

Roitt, I.M., Greaves, M.F., Torrigiani, G., Brostoff, J.

\& Playfair, J.H.L. (1969) The cellular basis of immunological responses. A synthesis of some current views. Lancet, ii, 367.

Rowley, M.J., Mackay, I.R. \& McKenzIE, I.F.C. (1969) Antibody production in immunosuppressed recipients of renal allografts. Lancet, ii, 708.

SERCARZ, E.E. \& BYERS, V.S. (1967) The X-Y-Z scheme of immunocyte maturation. III. Early IgM memory and the nature of the memory cell. Journal of Immunology, 98, 836

Skurkovich, S.V., Kisluak, N.S., Machonova, L.A. \& BEGUNENKo, S.A. (1969) Active immunization of children suffering from acute leukaemia in acute phase with 'live' allogeneic leukaemia cells. Nature (London), 223, 509.

Thomson, D.M.P., Krupey, J., Freedman, S.O. \& Gold, P. (1970) The radioimmunoassay of circulating carcinoembryonic antigen of the human digestive system. Proceedings of the National Academy of Sciences of the United States of America, 64, 161.

TING, A. \& MORRIS, P.J. (1970) Leukocyte antigens in renal transplantation. XI. The genetic control of HL-A. (Submitted for publication).

VAlENTINe, F.T. \& LAWRENCE, H.S. (1969) Lymphocyte stimulation: transfer of cellular hypersensitivity to antigen in vitro. Science, 165, 1014.

VAN ROoD, J.J. (1969) Tissue typing and organ transplantation. Lancet, i, 1142.

WALFORD, R.L. (1969) The isoantigenic systems of human leukocytes. Series Haematologica, $2,1$.

WARNER, N.L. (1969) The expanding family of human immunoglobulins. Medical Journal of Australia, ii, 506.

WARNER,|N.L. BYrT, P.N. \& ADA, G.L. (1970) Antigens and lymphocytes in vitro: Blocking of the antigen receptor site with anti-immunoglobulin sera. Nature, (London) (In press).

WARNer, N.L. \& Szenberg, A. (1964) The immunological functions of the Bursa of Fabricius in chickens. Annual Review of Microbiology, 18, 253.

World Health Organization Scientific Group (1966) Immunotherapy of cancer. WHO Technical Report Series No. 344 . 